\title{
AN OCTOPUS AND A CIRCLE AT THE BASIS OF A FRAMEWORK FOR THE EVALUATION OF SUSTAINABLE MOBILITY
}

\author{
Louiselle Sioui, Catherine Morency, Hubert Verreault \\ Dept of Civil, Geological and Mining Engineering, Polytechnique Montréal, Canada
}

Submitted 30 November 2014; resubmitted 9 May 2015, 2 July 2015; accepted 5 August 2015; published online 29 March 2016

\begin{abstract}
Worldwide, transportation authorities are keen to implement sustainable development measures and to move toward a more sustainable mobility for people and goods. However, this implementation entails a rise in the need for a sustainable development assessment framework for mobility, in order to compare different projects or to monitor a given area. This paper addresses the issue of conceptualization and standardization of the evaluation of sustainable development in transportation, by proposing a framework, which seeks to meet the various needs of transportation planners. This framework aims to provide an exhaustive view of the sustainability features (through its three main dimensions), as well as to clarify the concept of sustainability in transportation by embedding links between actions and impacts. This paper presents the basis of the framework developed as an interactive tool: (1) a representation named 'Octopus' categorizing the impact of mobility on the three dimensions of sustainable development and (2) a circular representation, named 'Causal circle', which integrates causal links between actions and impacts on these same dimensions.
\end{abstract}

Keywords: sustainability; sustainable transport; sustainable mobility; evaluation; indicators; causal chain; impact; framework.

\section{Introduction}

The implementation of transport sustainability causes growing concerns among public authorities. Policymakers want to justify their actions with regard to sustainable mobility. Yet, there is no standardized tool to identify which phenomena to measure, what indicators to use and how these indicators should be estimated. The main objective of this research is to develop a sustainable mobility evaluation framework to guide planners in their decision process using a set of indicators with relevant estimation methods. At the light of the current literature on the impacts of mobility on sustainability as well as of the existing systems of indicators, we conclude that there is still some clarification needed with respect to indicators selection and linkage between them.

This research aims to provide a tool, which facilitates the selection of indicators to be measured when evaluating sustainable mobility as well as address the challenges faced with current practices namely the lack of theoretical justification and redundancy issues. More specifically, it aims to:

- clarify the concept of sustainable mobility by structuring the multiple impacts of mobility on the three dimensions of sustainability;

- meet the various needs of the transportation planners and be adaptive with regards to the social context;

- integrate causal links between transport supply, travel demand, and mobility impacts.

This paper proposes a creative way to organize the multiple topics lying under the concept of sustainable mobility. Interactive features allow the proposed tool (Sioui 2015) to adjust itself to various evaluation needs, such as monitoring the progress of a specific program, comparing interventions on a corridor or giving a global appreciation for a given area. These evaluation needs can also relate to a local, a regional, or a global perspective.

The paper is organised as follows: first, some background elements related to sustainability measures and existing systems of sustainability indicators are presented. This section leads to the identification of research gaps in the domain. Then, the proposed assessment framework, organised in two views, namely the 'Octopus' and the 'Causal circle', is presented and discussed. On one hand, the Octopus diagram structures 
the impacts of mobility on the environment, society and economy in order to make the concept of sustainable mobility clearer, whatever the planner's priorities. On the other hand, the Causal circle shows relationships between transport supply, travel demand and the impacts of mobility. This interactive diagram (Sioui 2015) can be used to help anticipate the effects of an intervention on sustainability or to identify appropriate levers of action. It also provides support for the selection of indicators, by highlighting redundancy issues. The paper concludes with a discussion as well as some research perspectives.

\section{Background}

\subsection{Sustainable Mobility as an Ambiguous Concept}

The will to implement sustainable mobility emerges from the broader vision of implementing sustainability in all human activities (Hardy 2011). The most common definition comes from the Brundtland Report (WCED 1987), which claims that sustainable development is one that meets the needs of the present without compromising the ability of future generations to meet their own. Since it is based on unknown future developments (needs, knowledge and technologies), this definition is vague (Gudmundsson, Sørensen 2011) and contains uncertainty (Vivien 2003). Even though its theoretical insufficiencies complicate the implementation of sustainability, this definition is adopted worldwide.

The lack of specific elements in the definition creates ambiguity, but it also justifies the need for appropriation by whoever or whatever domain aims for sustainability. In fact, this contextual appropriation ensures that sustainability is a goal pursued whatever the scale, the location or the knowledge. Therefore, an appropriate definition needs to be developed for each specific context and it will influence priorities. Any attempt to develop a standardized framework to assess the sustainability level of mobility must address this issue of adaptability to context.

Consequently, there are various interpretations of sustainable mobility (Gendron, Revéret 2000) and many researchers and organizations have their own definition. A common way to elaborate one's own definition is to split the latter into a list of impacts on three dimensions: environment, society and economy (TRB 1997; Gilbert et al. 2002; Deakin 2001; Verry, Nicolas 2005). Though some definitions focus solely on one dimension, the goal is to achieve a balance between all three (UN 2012). Still, the lack of a common definition places sustainable mobility at the centre of a live debate (Marsden et al. 2010) that promotes innovation (Bouni 1998), and also increases local ownership (Zuindeau 2006).

\subsection{Existing Systems of Indicators}

The impacts of mobility on the three dimensions of sustainability are abundant. Thus, several systems of indicators have been proposed by researchers or organizations, some of which are summarized in Jeon and Amekudzi (2005), and Nichols et al. (2009). Other than Litman's (2015) one, these systems are developed for differ- ent scales of analysis, namely metropolitan (Rodrigues da Silva et al. 2010; Lautso 2004; Maoh, Kanaroglou 2009; Verry, Nicolas 2005; Castillo, Pitfield 2010; Jeon et al. 2013) or national (Gilbert et al. 2002; Johnston, Gao 2009). They are not developed to be applied simultaneously to several scales and approaches such as: the state, the metropolitan area, the neighbourhood, the transportation corridor, the individual, and the trip generator. Furthermore, the existing systems aim to either monitor the progress or compare different scenarios. However, none are designed to reach both goals.

An important criterion for the selection of an indicator is its measurability, which requires data availability (Gudmundsson 2002). Therefore, it is usually the case that impacts for which no data is readily available are not taken into account in the indicator systems (Zegras 2006).

In addition, the multiplicity of issues in sustainable mobility causes the set of indicators to be presented in a list, often categorized into the three dimensions of sustainability. Given the diversity of impacts of mobility, the lack of structure can be cumbersome. Thus, we believe that such complex frameworks should be supported by visual representations.

Finally, the quantity and variety of impacts make it difficult to simultaneously consider multiple indicators in a decision process. Therefore, some existing systems of indicators propose an aggregated index, in which each indicator is assigned a weight (Rodrigues da Silva et al. 2010; Lautso 2004; Maoh, Kanaroglou 2009; Castillo, Pitfield 2010; Jones et al. 2013). However, this aggregation covers up a redundancy issue, which should be minimized (Joumard et al. 2011) to limit the risk to bias the decision process by taking into account one impact more than once. For instance, an impact on the environment may modify public health and, in turn, generate health care costs. Here, a single issue overlaps all of the three dimensions of sustainable development. Therefore, if multiple indicators of the same system have causal links, they may be of significant influence in a single index and in the decision-making process.

\section{Proposed Evaluation Framework}

\subsection{The Octopus}

This first diagram relies on a literature review of the numerous impacts of transportation supply and demand (transportation infrastructures, vehicles, traffic, congestion, mobility behaviours, etc.) on various subject areas: people, wildlife, flora, water, air, soil, local and regional economy and vitality, costs and revenues for individual and community. As shown in Fig. 1, the result is a broad scheme titled 'Octopus' and composed of multiple ramifications which concern various subject areas. Each impact or category of impacts is represented by a coloured circle.

The diagram has four levels and is based on the following principles. First, each impact is categorized into one of the three dimensions of sustainability (level 1). Second, impacts found in the literature are clas- 


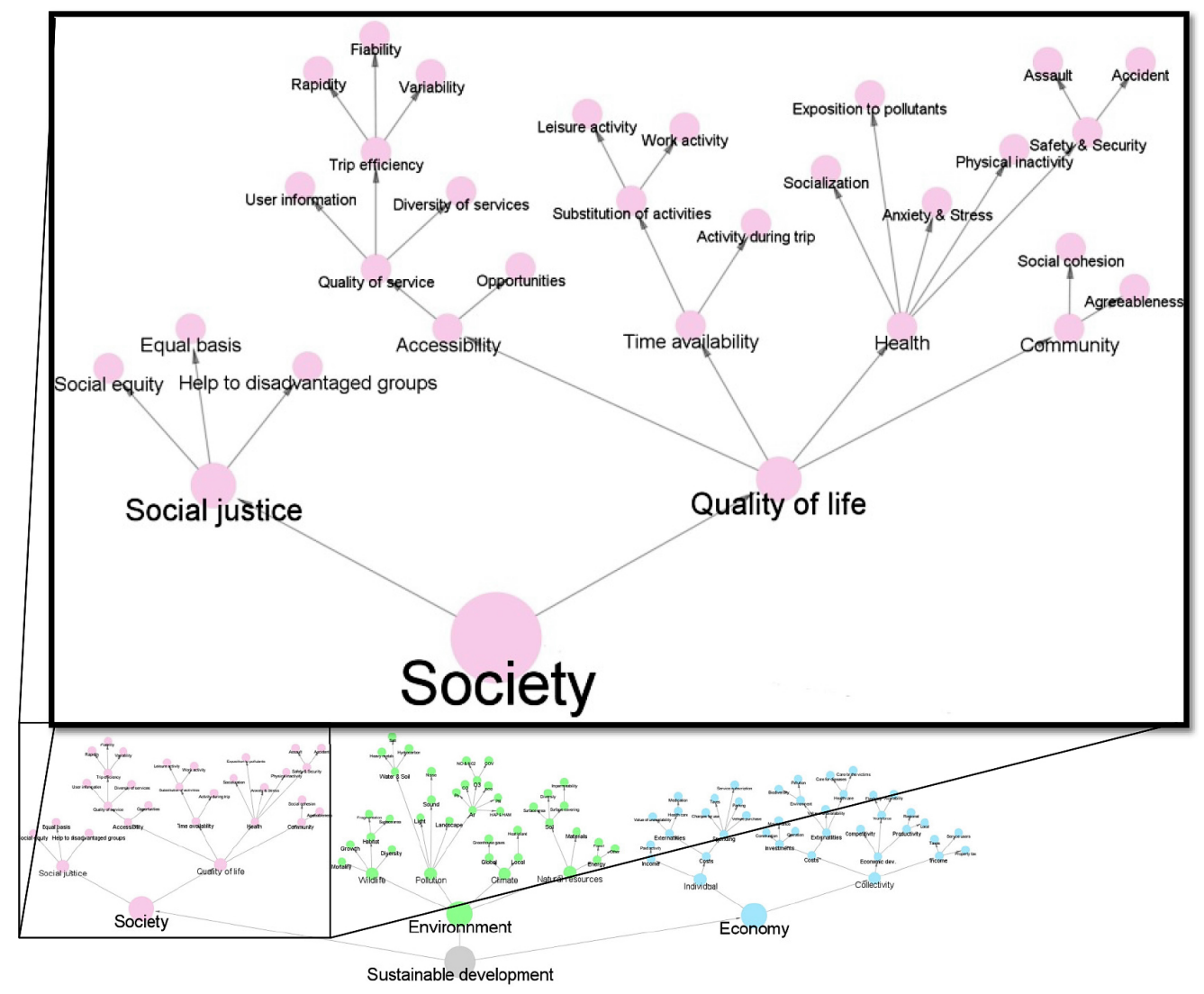

Fig. 1. The Octopus, focused on the social dimension (Sioui 2015)

sified into a small number of main categories organized in each dimension (level 2): social justice and quality of life in 'Society'; wildlife, pollution, climate and natural resources in 'Environment'; individual and community in 'Economy'. For each main category, impacts are classified as subcategories. When literature frequently groups together several impacts (level 4), these are placed into a subcategory (level 3). Here are some details on the impacts relating to each main category of each dimension. In 'Society', 'Social justice' has three subdivisions: equity, equal basis and social exclusion. 'Quality of life' includes four subdivisions, each one regrouping various impacts: health (socialization, exposure to pollutants, stress, physical inactivity, safety and security), accessibility (quality of transport supply and opportunities), time availability (substitution of activities and activities during trip) and the community (agreeableness and social cohesion). Fig. 1 illustrates the Octopus as well as a more detailed view of its social dimension.

The environmental dimension is divided into four main categories:

- pollution, which regroups water, soil, air, sound, light and landscape;

- natural resources, containing energy, materials and land;

- climate, either global or local;

- wildlife, including impacts on diversity, habitat, growth and mortality.

The economic dimension contains an individual and a collective level. The individual level includes costs of travel (purchase, usage and maintenance costs of a vehicle), its externalities (time lost during travel, health care) and income from work activities. The collective level consists of the investment costs (construction, operation and maintenance of infrastructures) and costs of externalities regarding social and environmental mitigation measures, income from taxes and various fees, as well as economic development (competitiveness and productivity of an area, flexibility and availability of labour).

Wide yet structured, the Octopus clarifies sustainable mobility by organizing its underlying concepts. Some impacts are affected by others, in the same or another category. For instance, in the social dimension, quality of service is linked with the opportunities that people can reach. The Octopus does not aim to represent these links, but rather to state the multiple impacts and contents of the various topics relating to sustainable mobility in a classified and hierarchical manner. By looking at the Octopus, transportation planners can quickly locate the impacts they have in mind within the three dimensions of sustainability. The diagram also helps to pinpoint forgotten impacts and to create a list of what impacts to consider.

In addition, some impacts can overlap across several dimensions. In this case, they appear in more than one of them. For instance, pollution is in the dimension 'Environment', its impact on public health is in the social dimension and the external costs of pollution (health care costs) are in the economic dimension. This overlap 
confirms that the Octopus is not the best diagram to assist in the selection of indicators. It also questions the relevance of quantifying each impact into one indicator system. Indeed, there would be too many indicators to take into consideration, and the causal links between them would cause redundancy issues.

\subsection{The Causal Circle}

In order to address these issues, a second representation has been developed. It aims to:

- integrate transportation supply and demand, as well as their impacts, into one single diagram;

- make causal links explicit;

- synthesize the multiple impacts of mobility.

Firstly, the literature review has pointed out supply and demand topics that planners aim to modify using the available mechanisms, in order to reduce negative impacts and enhance benefits of mobility. A total of 26 topics are identified:

- with relation to vehicle characteristics: energy consumption rate, greenhouse gases and various pollutant emission rates, engine efficiency, other features such as vehicles' capacity;

- with relation to trip characteristics: vehicle occupation rate, motorized travel distance, nonmotorized travel distance, travel time, path optimization of the trip, travel speed;

- with relation to individual characteristics: ecodriving, number of trips, physical energy expenditure, vehicle ownership or transportation service's subscription (transit, car-sharing, bikesharing, etc.);

- with relation to network characteristics: comfort and extra services, presence of infrastructure, universal accessibility to infrastructure, reliability and regularity of service, parking availability, variety of fares, network connectivity, information and signals, flows on the network, design quality (aging and safety), accidents, victims and sense of security, network capacity, volume/capacity ratio (congestion), energy prices.

Secondly, the literature review was also helpful in identifying each causal link between transportation supply, demand and impacts. Thirdly, in order to limit the size of the diagram, the numerous impacts listed in the Octopus are grouped into a limited number of issues according to the similarity of their causes and impacts: six social topics, ten environmental topics, and eight economical topics. The idea behind the visualisation is that when a causal link exists, two topics are interconnected by an arrow pointing to the effect. Since there is much information to present, several box diagrams are created to prevent lines from crossing.

Fig. 2 shows one of these diagrams, which focuses on land use consumption and urban heat islands. Covered by an impermeable and non-vegetal surface, transport infrastructures take land space. They fragment the natural habitat of species and therefore generate environmental costs. Water runoff on impervious surface puts pressure on other infrastructures, such as the wastewater system. Together with the presence of greenhouse gases, non-vegetal areas enhance urban heat islands, reducing the agreeableness of the local community and the health of individuals, as well as possibly changing social equity. Many of the issues cited in this example are included in other diagrams, which are focused on other issues (this is shown by double-sided arrows in Fig. 2). For instance, other box diagrams connect the network capacity to the presence of infrastructures. The transport infrastructures are also related to construction, operation and maintenance collective costs.

Finally, a circle shape with interactive properties was chosen to integrate all these box diagrams into one representation, entitled the 'Causal circle' (shown in Fig. 3). With a total of 49 topics, the upper part of the circle includes the 26 topics of supply and demand for transport. The lower part contains the social, environmental and economic impacts. In front of each impact

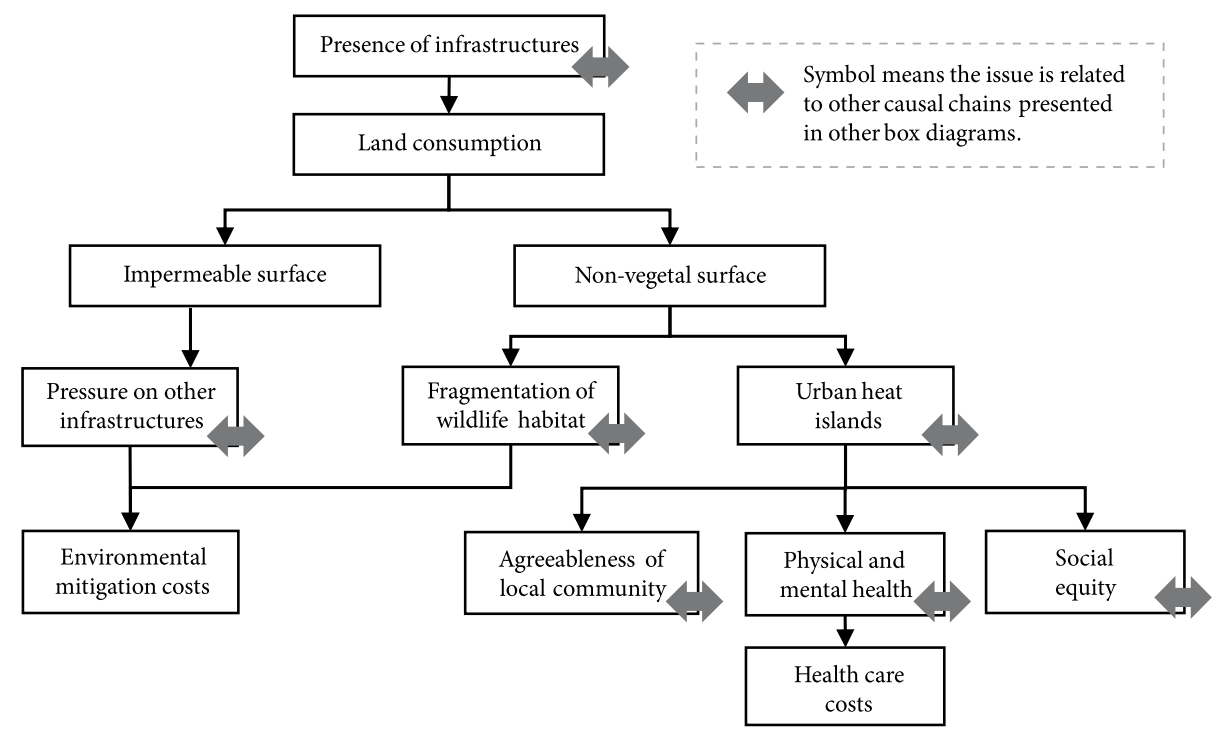

Fig. 2. Causal chains diagram focused on the presence of infrastructures 


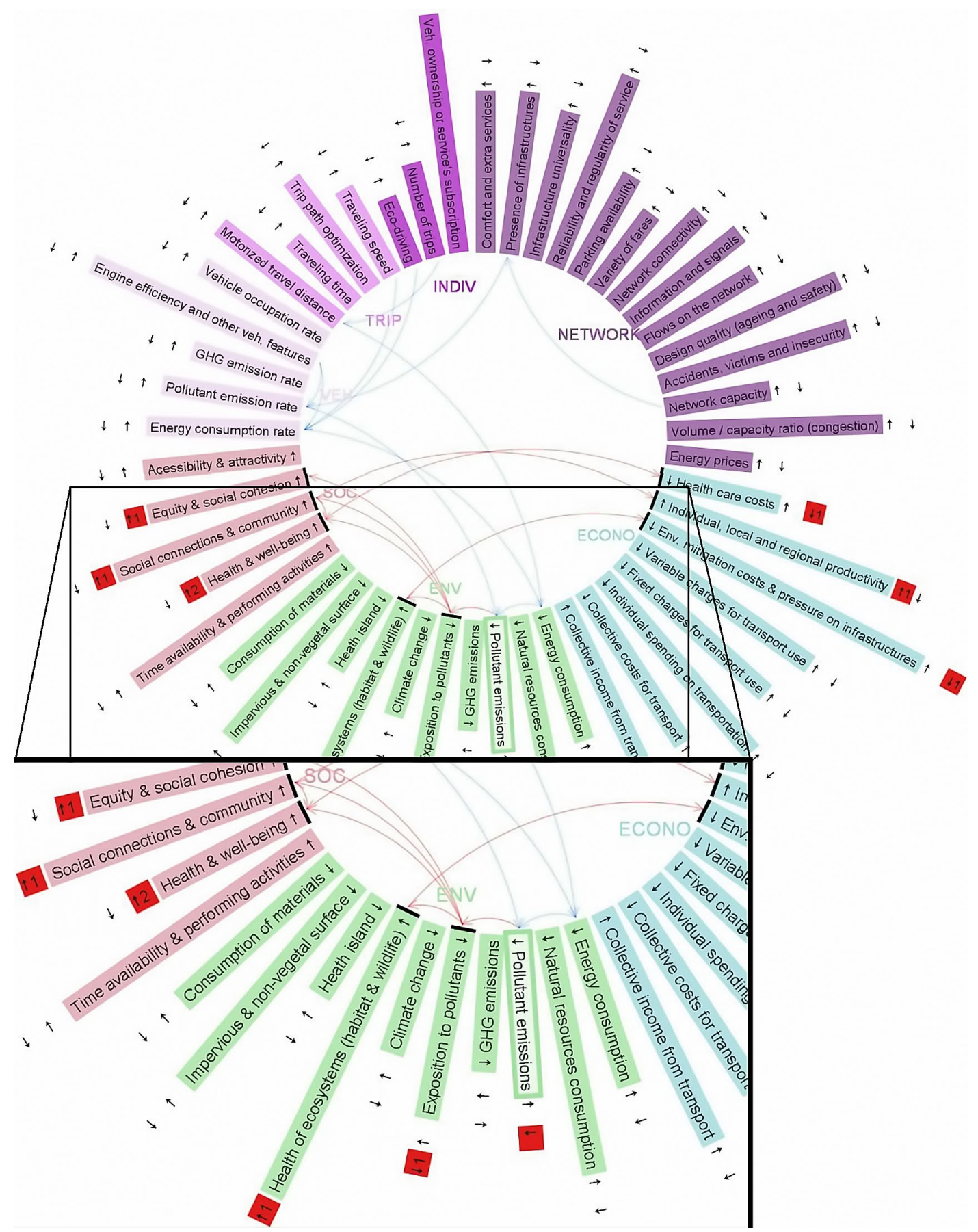

Fig. 3. The Causal circle, reduction of the emissions of pollutants (hierarchy level 2, automobile) (Sioui 2015)

is a desired ultimate direction to select: a reduction ' $\downarrow$ ' or an increase ' $\uparrow$ ' of the impact.

The Causal circle highlights many topics and impacts with their interconnections. These relationships are shown by arrows that appear in the circle when a topic is selected using the cursor. Blue arrows show topics that have an effect on the selected one. Red arrows show the effects of the selected topic on others. A definition of the selected topic is also displayed. When choosing a topic, a direction (reduction or increase) must be specified in order to represent the plausible outcome from a planned intervention. The diagram indicates if the effects on the other topics are positive or negative. The 'Hierarchy level' button adjusts the causal chain and displays, for the selected topic, up to five levels of causal chains (direct impact being level 0). Each increase in the hierarchy level adds a layer of impacts relating to the causal chain of the topic touched by the preceding causal ending arrows. Finally, the 'Mode of transportation' button resizes the circle by keeping only the topics related to the selected mode. For instance, the emission of pollutants is filtered out when accounting for walking and cycling only.

As an example, let us suppose a transportation planner is concerned about reducing the emissions of at- 
mospheric pollutants. Fig. 3 illustrates this example: the cursor points a decrease ' $\downarrow$ ' of the pollutant emissions; a hierarchy level ' 2 ' is selected as well as 'automobile' for transportation mode. The tool (Sioui 2015) reveals the anticipated effects of this change on other social, environment and economic impacts. The red arrows indicate a decrease in the population's exposition to pollutants, resulting in an improved health and well-being of individuals as well as an increased agreeableness of the local community. The latter impact has, in turn, a positive effect on the well-being of individuals. Therefore, the health and well-being topic is affected positively twice, justifying the red notice ' $\uparrow 2$ '. This cumulative characteristic is helpful: here, it emphasizes the health impact and guides the planner's thoughts to consider it as an impact of greater concern. In other cases, it can reveal opposite effects from distinctive paths, such as simultaneous ' $\uparrow 1$ ' and ' $\downarrow 1$ ', which indicate that the planned intervention has both positive and negative impacts on a specific element.

In the example, the red arrows of the Causal circle also highlight that a change in the exposition to pollutants may present equity concerns, that a better health status may reduce health care costs and that a higher agreeableness of a neighbourhood may benefit to the local productivity. Humans are not the only ones exposed to pollutants. The wildlife is also exposed, and thus, less environmental mitigation measures and costs are foreseen.

The blue arrows show the topics that influence the emission of pollutants, such as the motorized trip distance, which is dependent on the number of trips of individuals. Finally, when a topic in the Causal circle is selected, the affected impacts in the Octopus are illuminated. It gives a quick insight of the affected impacts and helps notice if all of the three dimensions of sustainability are involved.

When the transportation planner is creating a set of indicators, the tool (Sioui 2015) helps him to determine whether these indicators are interconnected, and in what way. It also clarifies the extent to which the selected indicators are measuring the same phenomena (redundancy issue). The tool can assist to reduce the number of indicators included in the final set while ensuring the comprehensiveness of the assessment. In this example, measuring the exposition of the population to pollutants, health problems or cost of health care clearly requires indicators, which rely on more than simple mobility data. It also requires some simplifying assumptions to isolate the contribution of transportation. Therefore, measuring the emission of pollutants may be simpler, and still give a good insight of the evolution of its subsequent impacts. In order to better interpret the observed evolution of the quantity of pollutants emitted, the blue arrows suggest contextual indicators: the pollutant emission rates of the vehicles, the energy consumption rate of the vehicles and the motorized travelled distance. Furthermore, if no data is available to measure one specific impact, the Causal circle identifies the causes that could otherwise be monitored.

\section{Discussion and Perspectives}

This research offers a unique, consistent and interactive overview of sustainable mobility, while linking together transportation supply, travel demand and their impacts on the three dimensions of sustainable development. The proposed framework is based on two schematics, namely the Octopus and the Causal circle. The former illustrates the concept of sustainability applied to transportation with an extensive view of the various features of the three dimensions of sustainability while the latter shows the causal links between the impacts and the directions for which topics may change.

Developed as an online, interactive tool (Sioui 2015), the framework highlights the topics of interest concerning sustainable mobility. Policymakers who wish to implement sustainable mobility can adapt the concept with regard to their social context (time, place) and their interests. According to the context and to his priorities, the planner can rely on the tool as a basis for developing an appropriate definition of sustainable mobility or for building a set of indicators. The tool also helps to anticipate the effects of an intervention or a change in mobility behaviours, and enables the comparison of different scenarios. This framework helps transportation planners to have systematic, well-structured considerations, and to better anticipate the diversified set of effects, both unexpected and contradictory.

The tool will be enhanced with many other interactive features, currently under development. A set of indicators adapted to the topics that are selected in the Causal circle will be added to the actual framework as a third component. In order to better define the causal links, two attributes will be added: the size (small, medium, large) and the term (short, medium, long) of the effects. Furthermore, a major improvement is the integration of modal shift by creating a new view with several Causal circles, one for each mode of transport. When the modal split changes, it affects the number of trips in each of the Causal circles.

The tool will appear as an editable platform; the user may create a new transportation mode. Moreover, according to the needs and context of evaluation, topics of the Causal circle may be grouped or split. In addition, a new supply or demand topic may be added to the upper part of the Causal circle, and integrated into existing causal chains. In the long term, it will also be relevant to integrate land use parameters as these affect mobility behaviours.

Simultaneously to these technical improvements, an effort to formalize causal chains is put in place. Research has not reach the same stage for all of the issues, especially concerning the qualitative or societal concerns. For both of these, transportation planners have to debate on the relevance of their integration into the diagram. 


\section{References}

Bouni, C. 1998. Lénjeu des indicateurs du développement durable. Mobiliser des besoins pour concrétiser des principes, Nature Sciences Sociétés 6(3): 18-26. (in French). http://dx.doi.org/10.1016/S1240-1307(98)80079-4

Castillo, H.; Pitfield, D. E. 2010. ELASTIC - a methodological framework for identifying and selecting sustainable transport indicators, Transportation Research Part D: Transport and Environment 15(4): 179-188.

http://dx.doi.org/10.1016/j.trd.2009.09.002

Deakin, E. 2001. Sustainable Development and Sustainable Transportation: Strategies for Economic Prosperity, Environmental Quality, and Equity. Working Paper 2001-03. University of California at Berkeley, Institute of Urban and Regional Development. 41 p.

Gendron, C.; Revéret, J.-P. 2000. Le développement durable, Économies et Sociétés, Série F 37: 111-124. (in French).

Gilbert, R.; Irwin, N,; Hollingworth, B.; Blais, P.; Lu, H.; Brescacin, N. 2002. Sustainable Transportation Performance Indicators (STPI) Project. Report On Phase 3. Centre for Sustainable Transportation and IBI Group and Metropole Consultants. 125 p. Available from Internet: http://cst.uwinnipeg.ca/documents/STPI\%20Phase\%203\%20report.pdf

Gudmundsson, H. 2002. The role of performance indicators in sustainable transport policy, in K. C P. Wang, G. Xiao, L. Nie, H. Yang (Eds.). Traffic and Transportation Studies: Proceedings of the International Conference on Traffic and Transportation Studies (ICTTS) 2002, 23-25 July 2002, Guilin, China, 33-40. http://dx.doi.org/10.1061/40630(255)5

Gudmundsson, H.; Sørensen, C. H. 2011. The use and influences of indicators in European sustainable transport policy, in European Transport Conference 2011, 10 October 2011, Glasgow, UK. Available from Internet: http:// abstracts.aetransport.org/paper/index/id/3685/confid/17

Hardy, D. K. 2011. Sustainability 101: a primer for ITE members, ITE Journal 81(4): 28-34.

Jeon, C. M.; Amekudzi, A. 2005. Addressing Sustainability in transportation systems: definitions, indicators, and metrics, Journal of Infrastructure Systems 11(1): 31-50. http://dx.doi.org/10.1061/(ASCE)1076-0342(2005)11:1(31)

Jeon, C. M.; Amekudzi, A. A.; Guensler, R. L. 2013. Sustainability assessment at the transportation planning level: performance measures and indexes, Transport Policy 25: 10-21. http://dx.doi.org/10.1016/j.tranpol.2012.10.004

Johnston, R. A.; Gao, S. 2009. Public versus Private Mobility for the Poor: Transit Improvements versus Increased Car Ownership in the Sacramento Region. MTI Research Report 0802. Mineta Transportation Institute, College of Business, San José State University. 46 p. Available from Internet: http://transweb.sjsu.edu/project/2403.html

Jones, S.; Tefe, M.; Appiah-Opoku, S. 2013. Proposed framework for sustainability screening of urban transport projects in developing countries: a case study of Accra, Ghana, Transportation Research Part A: Policy and Practice 49: 2134. http://dx.doi.org/10.1016/j.tra.2013.01.003

Joumard, R.; Gudmundsson, H.; Folkeson, L. 2011. Framework for assessing indicators of environmental impacts in the transport sector, Transportation Research Record: Journal of the Transportation Research Board 2242: 55-63.

http://dx.doi.org/10.3141/2242-07
Lautso, K. 2004. The Propolis Approach to Urban Sustainability - Theory and Results from Seven European Case Cities, in European Transport Conference 2004, 4 October 2004, Strasbourg, France. Available from Internet: http://abstracts.aetransport.org/paper/index/id/1958/confid/10

Litman, T. 2015. Well Measured: Developing Indicators for Sustainable and Livable Transport Planning. Victoria Transport Policy Institute, Canada. 101 p. Available from Internet: http://www.vtpi.org/wellmeas.pdf

Maoh, H.; Kanaroglou, P. 2009. A tool for evaluating urban sustainability via integrated transportation and land use simulation models, Environnement Urbain / Urban Environment 3: 28-46. http://dx.doi.org/10.7202/037599ar

Marsden, G.; Kimble, M.; Nellthorp, J.; Kelly, C. 2010. Sustainability assessment: the definition deficit, International Journal of Sustainable Transportation 4(4): 189-211.

http://dx.doi.org/10.1080/15568310902825699

Nichols, J.; Garrick, N.; Atkinson-Palombo, C. 2009. A framework for developing indicators of sustainability for transportation planning, in TRB 88th Annual Meeting Compendium of Papers, 11-15 January 2009, Washington, DC, $1-15$.

Rodrigues da Silva, A. N.; Costa, M. S.; Ramos, R. A. R. 2010. Development and application of I_SUM: an index of sustainable urban mobility, in TRB 89th Annual Meeting Compendium of Papers, 10-14 January 2010, Washington, DC, 1-18.

Sioui, L. 2015. Sustainable Mobility Framework: the Causal Circle \& the Octopus. Available from Internet: http://chairemobilite.civil.polymtl.ca/imd/imd-en.html

TRB. 1997. Toward a Sustainable Future: Addressing the LongTerm Effects of Motor Vehicle Transportation on Climate and Ecology. Special Report 251. Transportation Research Board (TRB). Washington DC, USA, National Academy Press. 275 p. Available from Internet: http://onlinepubs. trb.org/onlinepubs/sr/sr251.pdf

UN. 2012. The Future We Want: Outcome document adopted at Rio+20. United Nations (UN). 49 p. Available from Internet: http://www.un.org/en/sustainablefuture

Verry, D.; Nicolas, J.-P. 2005. Indicateurs de mobilité durable: de l'état de l'art à la définition des indicateurs dans le projet SIMBAD. Rapport intermédiaire $\mathrm{n}^{\circ} 2$ du projet Simbad SImuler les MoBilités pour une Agglomération Durable. 99 p. Available from Internet: https://halshs.archives-ouvertes.fr/halshs-00101352 (in French).

Vivien, F.-D. 2003. Jalons pour une histoire de la notion de développement durable, Mondes en développement 1(121): 1-21. (in French). http://dx.doi.org/10.3917/med.121.0001

WCED. 1987. Our Common Future. World Commission on Environment and Development (WCED). Oxford University Press. 400 p.

Zegras, C. 2006. Sustainable transport indicators and assessment methodologies, in Biannual Conference and Exhibit of the Clean Air Initiative for Latin American Cities: Sustainable Transport: Linkages to Mitigate Climate Change and Improve Air Quality, 25-27 July 2006, São Paulo, Brazil, $1-17$.

Zuindeau, B. 2006. Spatial approach to sustainable development: challenges of equity and efficacy, Regional Studies 40(5): 459-470. http://dx.doi.org/10.1080/00343400600757437 